International Journal of Natural Sciences Research

2019 Vol. 7, No. 1, pp. 10-21

$\operatorname{ISSN}(e): 2311-4746$

$\operatorname{ISSN}(p): 2311-7435$

DOI: 10.18488/journal.63.2019.71.10.21

(C) 2019 Conscientia Beam. All Rights Reserved.

check for
updates

\title{
GREEN TRANSFORMATION AND ITS APPLICATION ON SHIPPING SERVICE COMPLEX
}

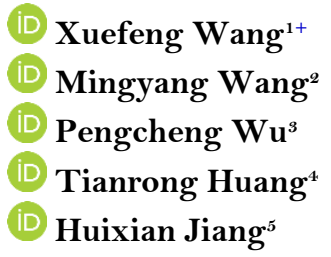

Article History

Received: 31 December 2018 Revised: 6 February 2019

Accepted: 12 March 2019

Published: 15 April 2019

\section{Keywords}

Green transformation

Energy-saving

Upgrade

SSC

Shanghai

Construction.

\author{
${ }^{1,2}$ College of Transport and Communications, Shanghai Maritime University, \\ Shanghai, China \\ 'Email: wangxf@shmtu.edu.cn \\ 'Email:womy1993 nh@163.com \\ ${ }^{s}$ Shanghai International Port Group Co., Ltd., Shanghai, China \\ 'Email:13818991239@139.com \\ "Shanghai Urban Construction Design and Research Institute (Group) \\ Co.,Ltd., Shanghai, China \\ 'Email: 564668558@qq.com \\ ${ }^{5}$ Shanghai Minyuan Vocational College, Shanghai, China \\ ${ }^{5}$ Email:huixian.jiang@shmy.edu.cn
}

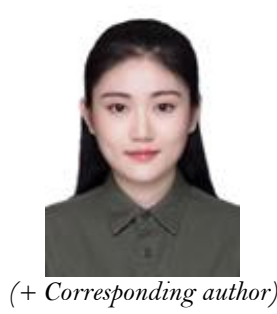

ABSTRACT

This article is written under the context of old construction Shanghai Shipping Service Complex (SSC) around the port. These buildings are too old to keep pace with the development and urgent to be upgraded. This article generally introduced the green transformation methods and application on the existing buildings in the urban old port district. In order to facilitate the green transformation of the SSC, we carried out an investigation upon the construction, structure design, specific building materials and interior decoration of the original building to form a general understanding. By combining its location features and functional orientation, the optimal transformation scheme was completed through the comparison of the building projects, structural analysis, and energy-saving transformation program. Meanwhile, the effect of the preliminary scheme was tested via energy-saving calculation, computer simulation and field testing. A third party was introduced to certificate the technological application to prove the safety and reliability of the scheme.

Contribution/Originality: This paper's primary contribution is finding the detailed process of upgrading the old port district. It's necessary for people to see the whole big picture while making a building scheme. Meanwhile, never forget the environmental conservation factors.

\section{INTRODUCTION}

With the increase of the population and the acceleration of energy consumption, there was an outbreak of the world's energy crisis in the 1970s. Countries started to recognize the importance of energy conservation, environmental protection technology and sustainable development. Greenhouse effect on earth leads to the melting glaciers which have been threatening the environment on which human beings depend for survival. Energy-saving and emission-reduction have become a common issue faced by mankind. As one of the main resource consumers and environmental pollutants, architecture has become the focus aspect of energy-saving and emission-reduction. To create architecture which is green and full of vitality is the goal that people are pursuing at present.

In the 21 st century, with the concept of sustainable development deeply rooted in society, the study of green building theory began to get more and more attention. According to the incomplete statistics [1] resources and raw materials used in the construction and ancillary facilities are accounted for $50 \%$ of all human getting from the 
natural. $50 \%$ of global energy is consumed in the process of building and operating these buildings. One-third of environmental pollution are air pollution, light pollution, acoustic pollution and water pollution, which are closely related to construction, and construction waste accounts for two-fifths of the total amount of waste all over the world. As a result, waste generated directly or indirectly from buildings poses a serious threat to human safety and health worldwide.

Old buildings at the port have been used for a number of years. So a green transformation is of great significance for reducing pollution and improving economic efficiency, and it is also capable of reducing the investment and waste in construction projects. At the same time, because China has a large number of buildings, which have a wide range and cost high energy consumption, therefore promoting the green transformation of existing buildings tends to help the whole society achieve goals of energy-saving and emission-reduction, and this is exactly what central or local government at all levels wants. For owners, through green transformation, preservation and appreciation of assets are realized by improving the comfort of living, reducing air conditioning or heating costs, and extending the life and service years of buildings. For property enterprises, the improvement of building quality through green transformation is able to reduce the expenses of daily maintenance and personnel costs, and also reduce the expenditure of electricity, heating and so on in public areas. Therefore, green transformation is a very meaningful event for all the participants and operators involved. It's technically weighty to carry out an event like this on Shanghai Transport Building of Port accordingly.

Let's see it from a higher level, economy and politics, this project, together with the surrounding Shanghai International Shipping Service Center (SSC), have constituted an important component of the intending SSC, which can contribute to the construction of SSC.

\section{LITERATURE REVIEW}

After the first world oil crisis, in order to save energy and reduce manufacturing and operation costs, some developed countries formulated building energy conservation standard, regulations and related policies, even established building energy-saving related certification and management system [2]. In addition to legislation and the establishment of relevant energy-saving standards, developed countries have also adopted a variety of economic measures, such as energy-saving subsidies, discount loans or tax cuts, to encourage beneficiaries to participate automatically [3] besides, there were also direct or indirect investment in the development of related products and technologies and in research on renewable, clean and new energy use, with significant human, material and financial resources. For example, Germany provided 30 years of low-interest rate loans and subsidies for cogeneration technology [4] while in 2001 the Japanese government provided nearly 1 billion dollars for building energy efficiency and new energy development.

Some government agencies have put forward their own specific energy-saving goals to promote and encourage the whole society [5]. For example, the United States has formulated the White House Energy Saving Plan to enable the energy-saving renovation of existing buildings to proceed smoothly. It was necessary to legislate on energy conservation, so we could make full use of the existing advanced technology, and enable the participants to obtain the corresponding economic benefits. Since the number of new buildings was much smaller than the number of existing buildings, if we only focus on the new buildings, but ignore to carry out the existing buildings energysaving transformation in time, the effect would not be very remarkable. In developed countries, the energy-saving activities of new and existing buildings are carried out at the same time, in this case they have achieved very good results. The total building area is increasing year by year, at the same time, the energy consumption is lowered.

In the 1990s, China began to study the energy-saving transformation of existing buildings [6] and selected Beijing, Harbin and Shenyang as pilot cities, the main object of which was residential buildings. China initiated to compile the industry standard of energy-saving reformation, such as Technical Specification For Energy-saving Transformation of Existing Heating Residential Buildings and three codes for energy-saving design of residential 
buildings, but there are no standard public buildings. With the gradual increase of public buildings, Shanghai took the lead in formulating and implementing the Standard of Energy Saving Design For Public Buildings in Shanghai on January 1, 2004. On July 1, 2005, China promulgated the first comprehensive national standard on energysaving design of public buildings-Standard for Energy Saving Design of Public Buildings [7] It's the symbol of the comprehensive development of energy-saving work of civil buildings in China. In order to implement this policy, many provisions of the standard have been listed as mandatory, and provinces and cities have also issued relevant provincial laws.

At present, many energy-saving reformation projects have been carried out in our country. However, most of these reformation projects are aimed at the exterior-protected construction of existing buildings exterior-protected construction. The air conditioning system is rarely reformed; especially the research on the reformation of buildings in the old harbor area is seldom involved.

\section{THE INVESTIGATION ON THE ORIGINAL CONDITION OF SSC}

\subsection{Location Analysis}

Located in the Golden Triangle area composed of Bund Wanguo complex, Lujiazui financial service area and North Bund, SSC is of great geographical location and plays an important role in the establishment of SSC.

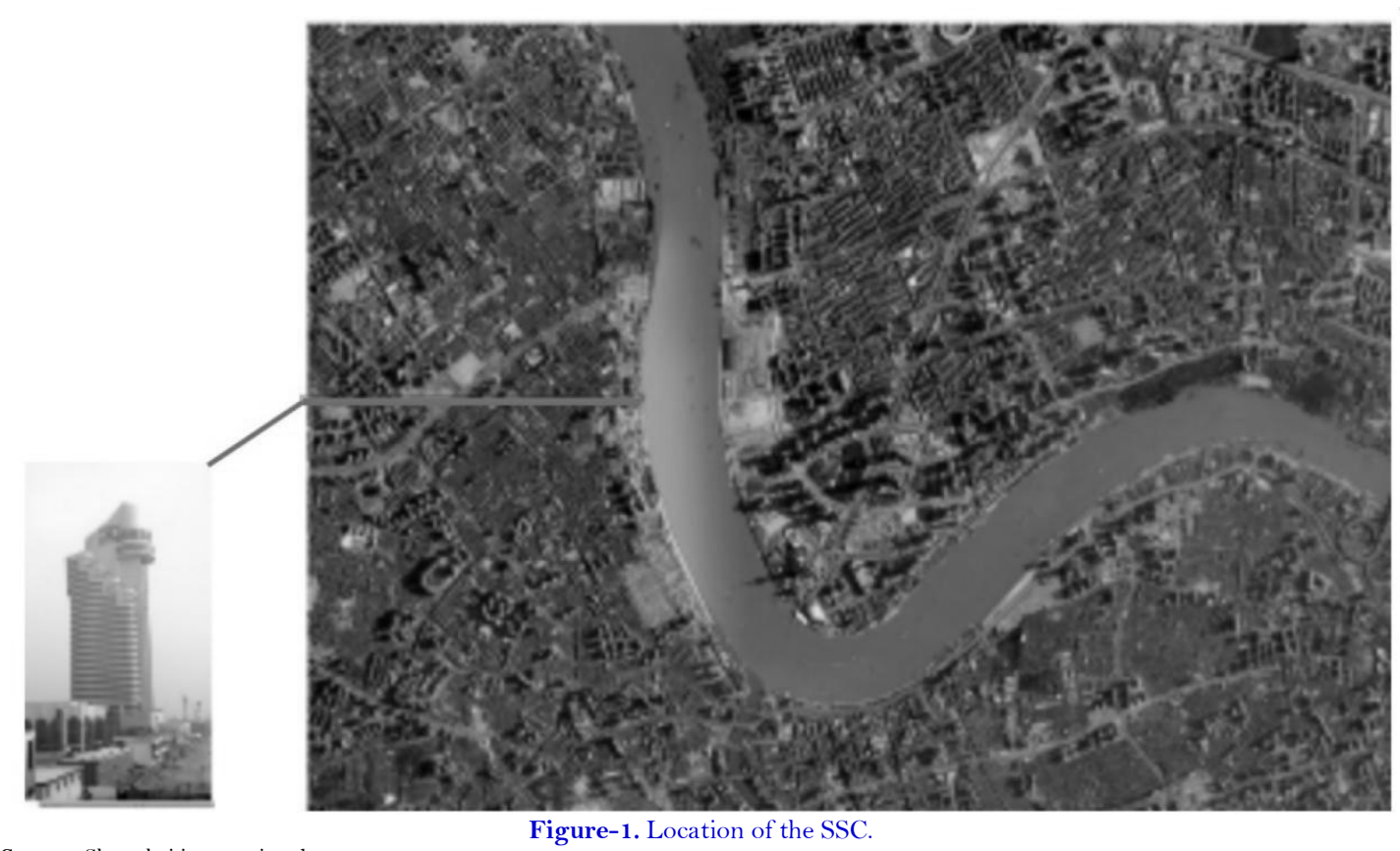

Source: Shanghai international port group.

Figure-1. Location of the SSC.

This project, which is located on the south side of North Bund, is one of the key areas for the development of Pujiang on both sides of Shanghai see Figure 1. The Bund starts from the junction of the Huangpu River and the Suzhou River in the west, and reaches Dalian Road in the east, covering an area of about 3.66 square kilometers, with a length of $3.53 \mathrm{~km}$ along the bank of the Huangpu River and the Suzhou River. The project is divided into 5 regions:

(1) Commercial and residential complex area (North Henan Road-Wusong Road)

(2) Commercial office building (west of Hongkou Port, east of Wusong Road)

(3) Shipping area (east of Hongkou port, west of Gongping road, north of Huangpu river, south of Changzhi road)

(4) Tilanqiao historical features and modern commercial street and shipping trading service area (east of fair road, west of Dalian road, north of Huangpu river, south of Tangshan road) 
(5) High-end residential area (south of Zhoujiazui Road, north of Hanyang Lu, west of Dalian Road, east of Wusong Road)

SSC, with important commercial value and historical and cultural significance, is located in the Tilanqiao historical features of the modern commercial street and shipping trading service area. And its status is relatively prominent and important.

In terms of transportation, a grid network is backed by the two horizontal and six vertical trunk roads with several branch roads and trams are arranged along the Huangpu River (Dongdaming Road-Yangshupu Road). There will be a total of 3 urban subway lines (M line) through the North Bund area.

This plan retains the existing 2 ferry lines of Taigong Line and Qiqin Line on the Huangpu River, which will be gradually improved according to the requirements of passenger flow and developed towards comfortable water buses in the future. There will be 2 to 3 cross-river carriageway tunnels connecting the north Bund and Pudong area on Huangpu River section in the future.

In addition, the Bund source and Exotic building clusters in the Bund of Shanghai are connected by the two bridges to the southwest of the North Bund; across the river, there we see the most dynamic financial and trade zone in Lujiazui, Pudong. After the World Expo, the North Bund, the Bund and Lujiazui have formed up a Golden Triangle of the Shanghai financial and trade zone.

This project planned to set up a large concentrated lawn square in the international passenger transport center north and seamen hospital west side base, with about 21000 square meters.

At the junction of Wusong road and east Changzhi road, a large area of 25000 square meters of green space is planned to be set.

A large public green space of about 26000 square meters is planned between Xiahai Temple and Moses Church.

In the commercial residential comprehensive area located in the west side of Wusong Road, combined with the original Kunshan Garden, it was planned to set up an area for an urban public green space of about 4,000 square meters and a riverfront along the Suzhou River green space of about 11,000 square meters.

On the whole, the architecture should be characterized by modern, simple and high-tech. In areas with protected building concentrated and blocks with historical features of basket-bridge and modern commercial elements, architecture should be embodied and characterized with tradition.

In the riverside part of the Huangpu River, there will be an inner harbor of yachts set up in the central part of the southern base in Tilanqiao historical features and the modern commercial streets. This is supposed to increase the richness and interest of public space and form an internal open space, together with the big green space in the west side of International Passenger Transport Center, an open space pattern is formed in the North Bund area.

\subsection{Function and Orientation}

This project of SSC is located in the Huishan plot in the north Bund of Hongkou District, Shanghai [8]. It starts from Qinhuangdao Road Ferry Station in the east, reaches the Gongping Road Ferry Station in the west, situated the proposed relocation of Dalian Road pump station to the north, and faces the Huangpu River in the south. Shanghai Huishan plot in the north Bund used to be storage wharf land, its north side is residential, office comprehensive land, west side of the Gongping Road for the new Bund Garden, the east for the Ruifeng Building commercial office project. The north of Yangshupu Road is the historical and cultural area of Tilanqiao. With the continuous promotion of the planning and comprehensive development of the two sides of the Huangpu River, the functions of the Huangpu River and its two sides have gradually shifted from the original transportation, warehousing, and industrial enterprises to focus on finance and trade, tourism culture, and ecological housing. The function conversion from production to comprehensive service is realized [9].

According to the national strategy of "Building Shanghai International Shipping Center", the Shanghai Municipal Party Committee and Municipal Government have issued relevant instructions and clear requirements 
for the new "Shanghai International Shipping Service Center Project". This project is aimed at setting up an international shipping trade zone, promoting the service level of Shanghai port and the capability of soft environment service. To achieve this goal, first, it is necessary to centralize the relevant functional departments of the municipal government, the supervision resources and the main customs clearance protocol of Shanghai port inspection units, so as to serve as a unified platform for the provision of government public services. The platform should involve "Port Inspection Customs Declaration Center", “Administrative Examination and Approval Center", "Customs Clearance Service Management Center", "Regional Audit Center", "International Navigation (Travel) Service Center", "Data Backup Center", etc. Second, gather domestic and multinational shipping enterprises to enhance the core function and scale effect of shipping services, complement the advantages of the port around the city, and interactively develop the multi-level shipping development service platform [10]. The SSC project is a high-quality and scarce resource of Shanghai International Port Group and even of Shanghai. It is located on the North Bund of Hongkou District and echoes with Lujiazui Financial Center across the river, covering an area of nearly 100,000 square meters. The 800-meter long landscape promenade alongside Huangpu River and 14 buildings represented by the new building of Shanghai Shipping Exchange are planned and built on the plot, with a total building area of nearly 600,000 square meters [11].

At present, the Shanghai Municipal Government and the Hongkou District Government have built the North Bund into a first-class modern cruise terminal dominated by Asia-Pacific route [12] combined with high-quality foreign affairs resources in the urban center and the North Bund. This project can be orientated as the core landscape business office building of SSC, attracting shipping companies, especially large liner companies, logistics enterprises, shipping agencies, cruise companies, maritime law business exhibition and other institutes to be settled. All of this is for the sake of the development of shipping market services, import and export logistics services and international passenger services and so many other relevant activities.

The original building has been for a long time, the color, shape, interior decoration and building energy-saving standards of which cannot keep up with the current requirements for the construction of an international shipping service center. It is urgent for the building to be rebuilt so that the building can display a good image as a landscape [13]. Figure 2 to Figure 5 showed views from every directions of the old building.

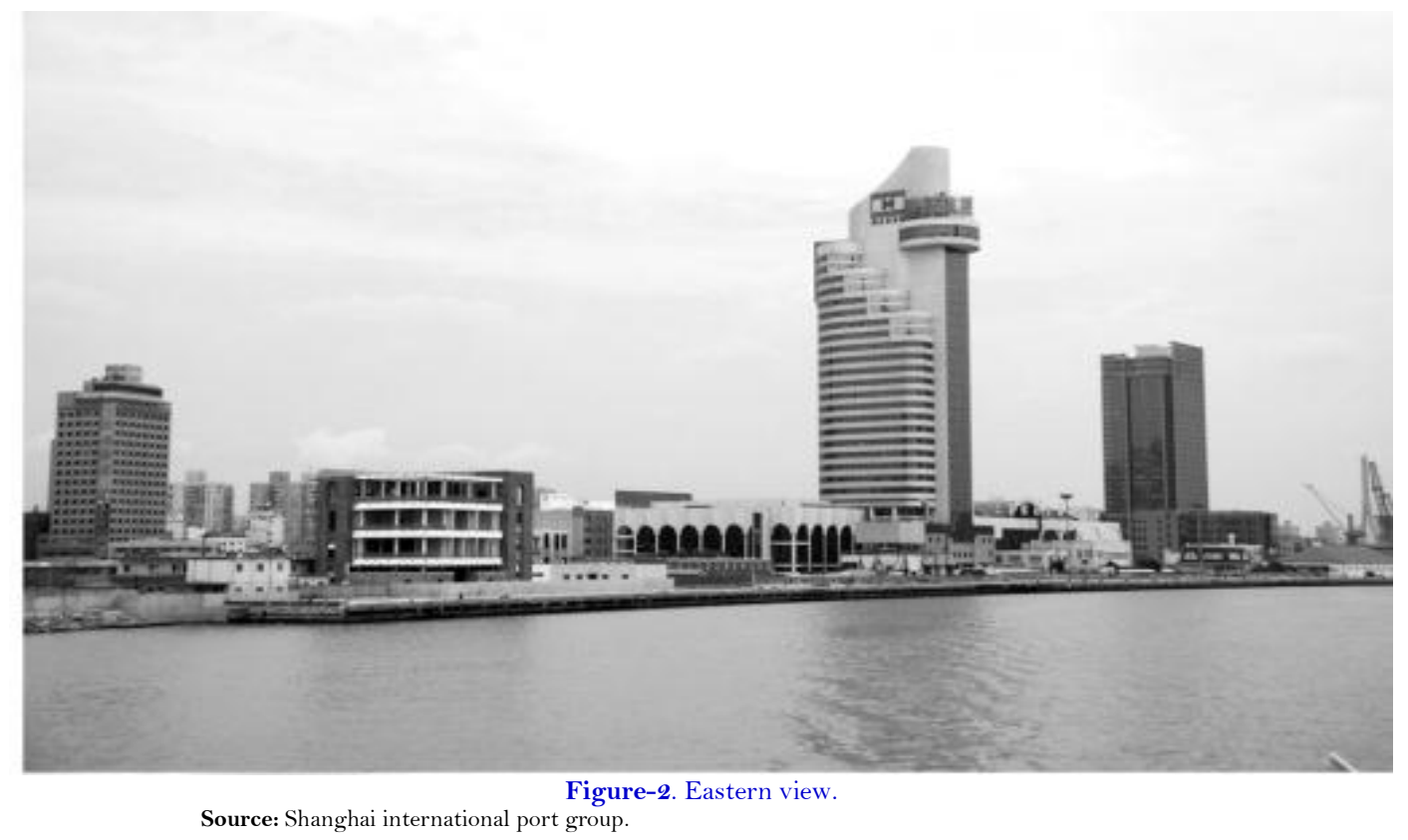




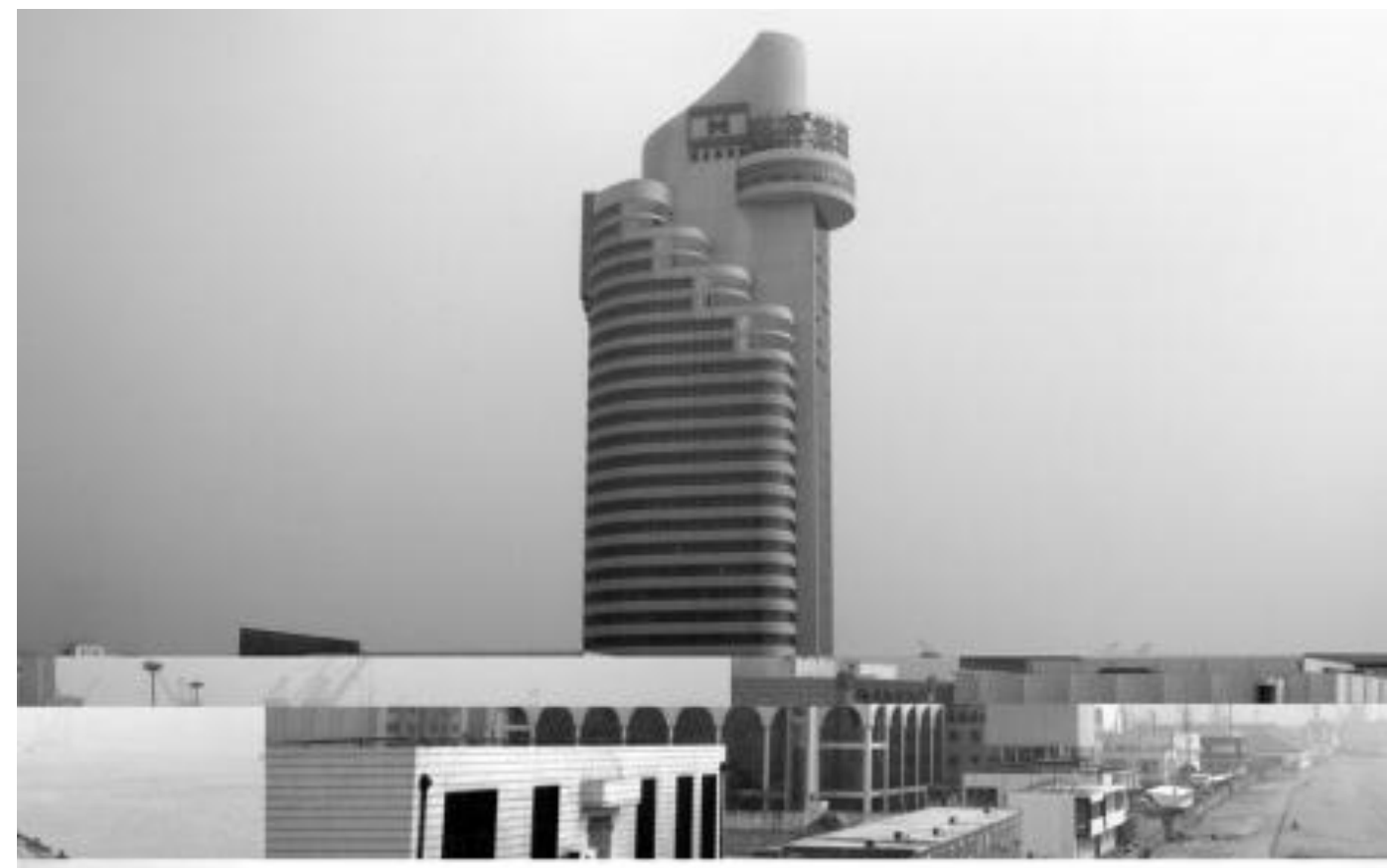

Figure-3. Southern view.

Source: Shanghai international port group.

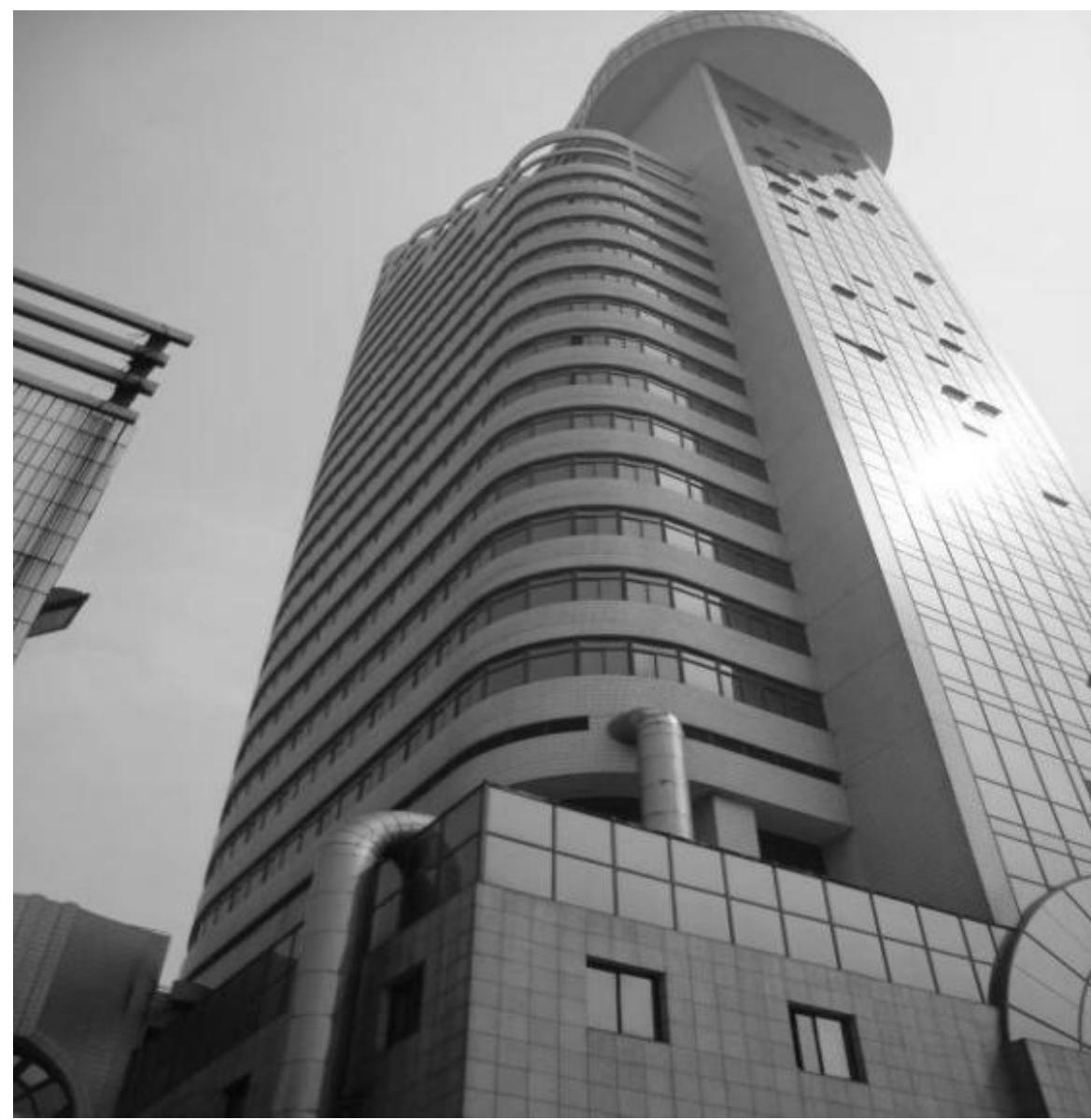

Figure-4. Western view.

Source: Shanghai international port group. 


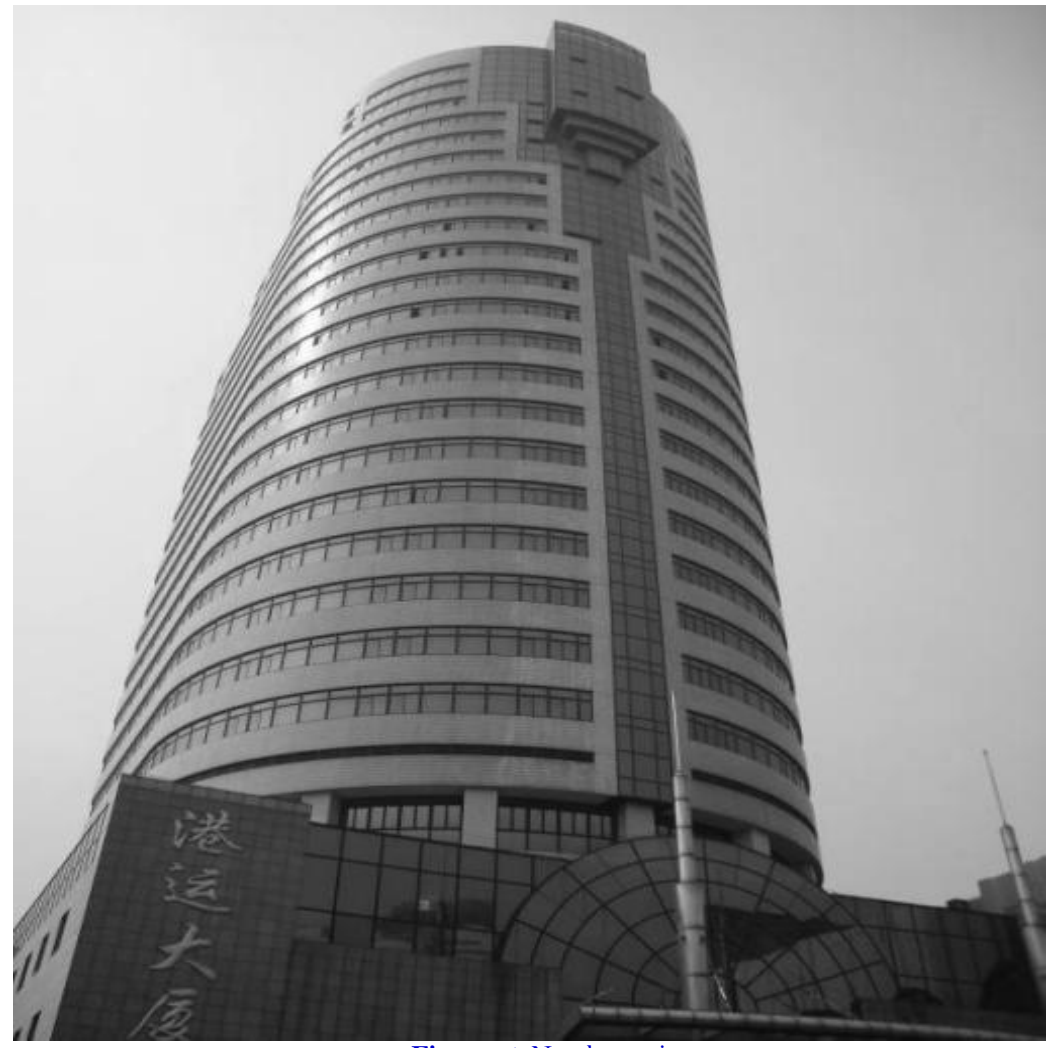

Source: Shanghai international port group.

Figure-5. Northern view.

\section{THE TRANSFORMATION OF SSC}

\subsection{Structural Transformation}

According to the request made by the Shanghai Municipal Party Committee and the municipal government, it is essential to merge the functions of the shipping exchange into its annex and lower floors. Together with the surrounding SSC, it will constitute an important part of the future SSC. The original layout can not meet the needs of the new situation, so we need to transform the turret.

The scheme provided by the architect shows the details. The floor plates of some floors are removed structurally, for the steel floor plates are added. The concrete core shear walls are added. After the transformation, the typical floor area is 42,500 square meters.

As for the annex, the new one is a three-story shipping house with the concrete slab-column shear wall structure. Annex's surface is 23.8 meters high, adjacent to the harbor basin. The superstructure is cantilevered above the second floor over the harbor basin, and the gravity effect caused by the superstructure is borne by the deep beams with variable cross sections and propagated to the columns and foundations. The structure has two floors below ground with concrete retaining walls on three sides. Install an aseismatic joint with distance of $100 \mathrm{~mm}$ between the annex and the main building on the ground. The height of the annex should be same as the turret with the corresponding floor. A number of post-pouring belts are set up in the basement to soften the effect caused by the long structure.

On the basis of the functional requirements of Shanghai Shipping Exchange and the scheme, all the interior and exterior decoration, partition walls and required equipment are removed. Strengthen the vertical lateral force resistant members (walls, columns), the horizontal members that have to be added to the floor for construction are removed; and the unnecessary floors are removed. For the vertical traffic organization in the trading hall of the exchange house running from the basement to the 3rd floor, 2 sightseeing elevators and 2 lifts are about to set up in the four-story high atrium, which is located between the main building and the annex. It not only solves the 
perpendicular traffic problem, but also enriches the space of the atrium. Figure 6 and Figure 7 showed a comparison of before and after the transformation.

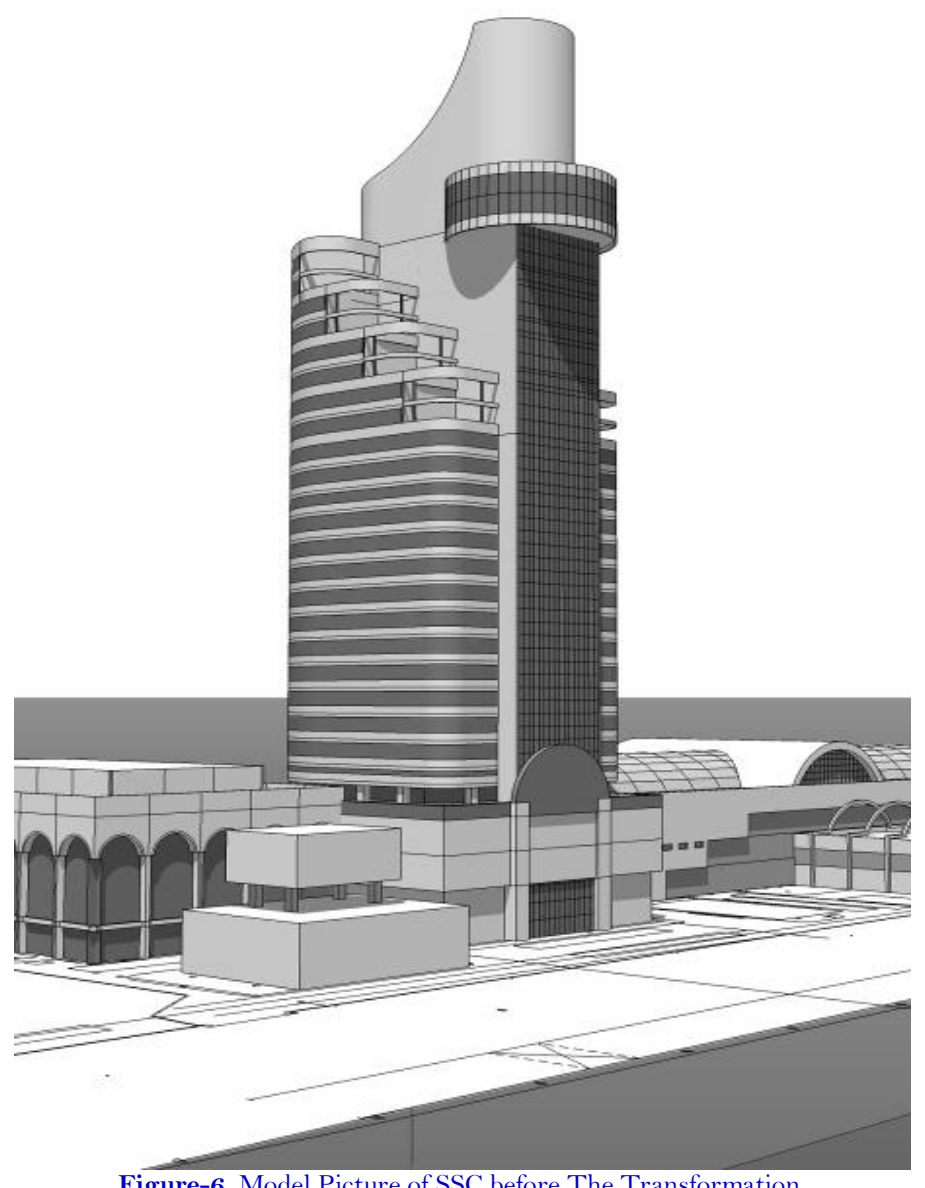
Source: Shanghai international port group.

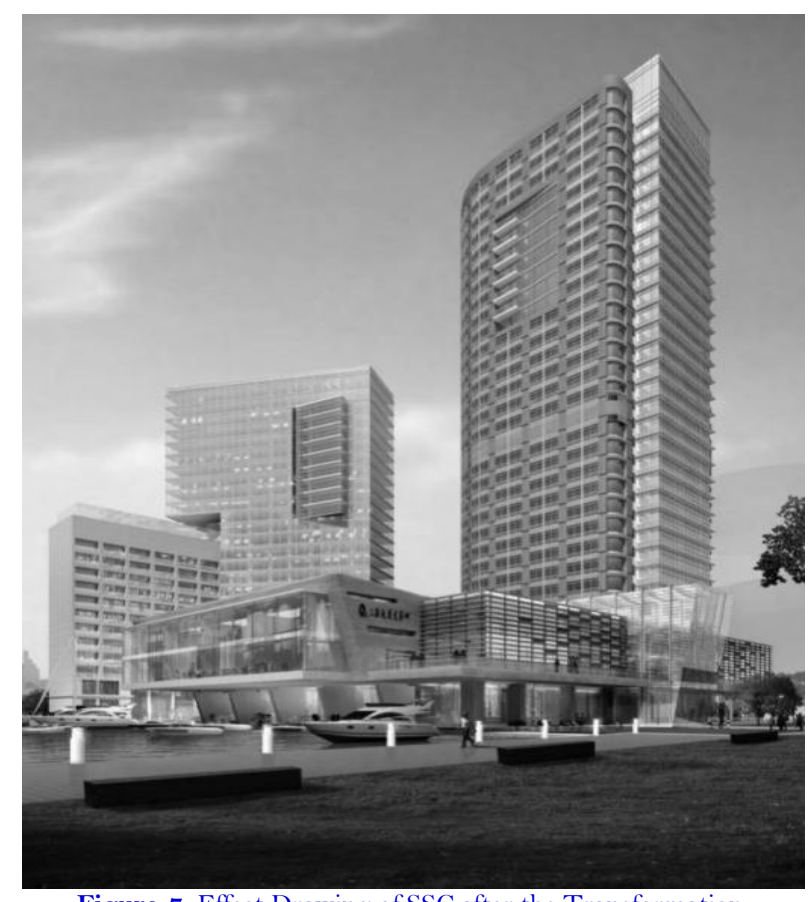

Figure-7. Effect Drawing of SSC after the Transformation. Source: Shanghai international port group. 


\subsection{Building Reconstruction}

\subsubsection{Color Scheme}

Color is caused by light, and light has its physical properties. The three primary colors (red, yellow and blue) are the basic elements of color composition. Hue, brightness, purity are regarded as the 3 elements of color. The 3 elements of color are the most basic attributes of color, also the basis in study [14].

Color contrast is referring to two or more colors, compared with space or time, when the clear difference stands out, it is called color contrast relation. The key of this concept is the contrast of three elements, which are contrast of color brightness and purity.

Lightness is the concept differentiates darkness and brightness of the color, and only moderate lightness contrast brings harmony. The sense of lightness in color matching can be considered from the aspects of high, medium, low-key, poor brightness and comprehensive factors.

Purity refers to the degree of brilliance of each color. Purity plays an important role in amplifying the theme and making various dramatic effects. The way of color matching according to the difference of purity between two colors is as important as the brightness contrast.

In terms of the functions of the color, red, orange, and yellow can make people cause heartbeat speed, blood pressure rises, and lead to the feeling of heat. Blue, purple, and green tend to lower blood pressure and slow down the heartbeat to bring a cold sensation.

Thus accordingly, in the transformation process of SSC, it will convey a warm and positive vibe to people if adopt warmer color and striking color contrast [15].

\subsubsection{Rational Combination of Architecture and Structure}

Architecture design and structural design is an essential step in the whole design process, which plays an important role in the appearance effect and structural stability of the building and there is a mutual coordination between the two. Therefore, the key in the green transformation of SSC to design buildings that are not only beauty in architecture, beautiful in shape, but also safe, economical and reasonable in structure.

The above-ground part of the main building of the previous SSC was 27 floors. As a result of the adjustment of the lower floors and the addition of the upper floors, the total number of floors above the ground has become 31 floors. The total height of the building is the same as before, and the absolute elevation of its highest point is still 132.1 meters. The height of the building is 124.6 meters. Since the increase in the number of floors, 4 passenger ladders originally located in the core tube of the main building could not meet the requirements for vertical transportation. By adjusting the core tube, passenger ladders were increased from 4 to 6.1 freight elevator and fire elevator installed in the core tube of the main building was maintained and the elevating height of the elevator was increased according to the condition of reconstruction.

By adjusting the storeys, the total height of the building is consistent with the original, and the better building plane, the facade and the space effect are achieved, which reflects the rational combination of the architecture and the structure.

\subsection{Energy-Saving Transformation}

\subsubsection{Exterior Walls}

In terms of energy consumption, exterior walls account for about $24 \%$ of the total energy consumption of the exterior-protected construction. Therefore, it is very important to strengthen the thermal insulation of the exterior walls [16]. According to the characteristics of regional climate, the energy-saving reformation of exterior walls of existing buildings is mainly about heat insulation and sunshade. It can be measured in three ways: (1) Install external insulation for external walls; (2) Plant green plants such as creepers, grapes and morning glory; (3) Install 
insulation for the other side of exterior walls. This is not commonly used in practice since its defects such as temperature instability. So it is just a backup plan. Figure 8 demonstrates the structure of walls.

\begin{tabular}{|l|l|}
\hline Tectonic diagram & Reinforced concrete wall \\
\hline 1-Foundation & fired common brick \\
\hline 2-bond coat & Concrete hollow block wall \\
\hline 3-insulating layer & Insulation boards \\
\hline 4-protective course & Rendering coating mortar and net \\
cloth \\
\hline 5-finishing coat & Architectural surface and covering \\
material
\end{tabular}

Figure-8. Thermal Insulation Structure of Exterior Walls.

Source: Author's research

\subsubsection{Exterior Doors}

The exterior doors is a part of the energy-saving reformation. Because of its regular opening, it will cause a great deal of cold wind invasion in winter, and heat invasion in summer. In addition, the material of the door will also affect the transfer of heat. In some remote small cities (such as those in the west), the doors are usually made of iron. We know that iron has a good performance on the heat transfer, but a bad performance on the thermal insulation. Therefore, wood doors and composite doors should be used as far as possible. Besides, the sealing of the door should also be taken into account.

\subsubsection{Exterior Windows}

Solar radiation is the main cause of indoor heat. Most of the windows in the buildings are single layer aluminum alloy. This kind of window has poor radiation protective effect, so the solar radiation heat almost all come straight through into the room, which leads to the increase of energy consumption of air conditioning and refrigeration in summer. In addition, poor air tightness further increases the energy consumption. Therefore, the transformation of windows is the heart of energy-saving transformation in hot summer and warm winter areas. In the case of incomplete reform conditions, priority should be given to the windows. 


\section{CONCLUSION}

This paper discussed the process of reforming a building into a new core landscape complex in the old port area. The starting point of the design is to create a new landmark along the Yangtze River with reasonable function and striking image through the rearrangement of the layout and the optimization of the exterior facade of the building. During the process of this project, all the design was made under the analytic results. The ratio of window to wall and the overall layout of the building are controlled according to the requirements of energy-saving, so as to achieve the comfort and energy-saving of the building from the architectural perspective.

Further research can be extended and focus on the following aspects: (1) enhance the informatization level in the process so as to carry out dynamic adjustments and guide the transformation work, thus improving the quality and efficiency of green transformation; (2) a quantitative comparative study can be conducted through the benefit analysis of energy-saving transformation; (3) new technology, materials and techniques are changing with each passing day. The adoption of more advanced, suitable and forward-looking technology requires more certification and practice.

Funding: This study received no specific financial support.

Competing Interests: The authors declare that they have no competing interests.

Contributors/Acknowledgement: All authors contributed equally to the conception and design of the study.

\section{REFERENCES}

[1] J. S. Jin and J. Wang, "Discuss the way to realize the substainable development of green building," Journal of Changchun University of Technology (Social Sciences Edition), vol. 03, pp. 75-78, 2006.

[2] B. Nicolae and B. George-Vlad, "Life cycle analysis in refurbishment of the buildings as intervention practices in energy saving," Energy and Buildings, vol. 86, pp. 74-85, 2015. Available at: https://doi.org/10.1016/j.enbuild.2014.10.021.

[3] C. F. Wang, "Legislation of energy saving from abroad and its reference," World Environment, (In Chinese), vol. o3, pp. 49-50, 2007.

[4] E. Sussman, "Reshaping municipal and county laws to foster green building, energy efficiency, and renewable energy," N.Y.U. Environmental Law Journal, vol. 16, pp. 01-43, 2008.

[5] R. Pacheco, J. Ordóñez, and G. Martínez, "Energy efficient design of building: A review," Renewable and Sustainable Energy Reviews, vol. 16, pp. 3559-3573, 2012. Available at: https://doi.org/10.1016/j.rser.2012.03.045.

[6] H. D. Guo, Y. X. Zhang, and Q. Q. Zhao, "International government regulatory experience of building energy-saving: A survey," Ecological Economy, vol. 3, pp. 291-300, 2017.

[7] N. Zhou and M. Levine, "Assessment of building energy-saving policies and programs in China during the 11 th FiveYear plan," Energy Efficiency, vol. 5, pp. 51-64, 2012. Available at: https://doi.org/10.1007/s12053-011-9111-0.

[8] Y. X. Lin, "Construction of Shanghai International Shipping service center begins," Science \& Technology of Ports, vol. 5, pp. 48-48, 2009.

[9] M. X. Chen, "Reflections on the development of waterfront areas on both sides of the Huangpu River in Shanghai " Journal of Yunnan University of Finance and Economics: Social Sciences Edition, vol. 18, pp. 65-66, 2003.

[10] Y. Dai, J. Q. Lu, and G. Wang, "The influence of the construction of Shanghai International Shipping Center on the economic development of Shanghai " Containerization, vol. 7, pp. 13-16, 2000.

[11] Z. H. Li, "Research on the construction of Shanghai International Shipping Center," Master Dissertation, Shanghai Normal University, 2010.

[12] H. Chi, "Building North Bund shipping service industry around Shanghai International Shipping Center," Journal of Shanghai Maritime University, vol. 25, pp. 10-11, 2004. 
[13] R. Y. H., L. B. R., and Y. H., "Structural design of Shanghai transport building of port reconstruction and extension," Building Structure, vol. s2, pp. 205-208, 2010.

[14] M. Ye, "Three basic elements of color," China Photographic Nerwspaper, vol. 014, pp. 06-03, 2016.

[15] S. H. Yang and F. Y. Zhu, "Research on color design in urban architecture," Construction Materials E Decoration, vol. 30, p. $126,2018$.

[16] L. Li, "Study on the construction mode of exterior walls greening in hot-summer area," Doctoral Dissertation, Huazhong University of Science and Technology, 2011.

Views and opinions expressed in this article are the views and opinions of the author(s), International Journal of Natural Sciences Research shall not be responsible or answerable for any loss, damage or liability etc. caused in relation to/arising out of the use of the content. 